Pacific Journal of Mathematics

SOME GENERALIZATIONS OF SCHAUDER'S THEOREM IN

V OT 


\section{SOME GENERALIZATIONS OF SCHAUDER'S THEOREM IN LOCALLY CONVEX SPACES}

\section{VOLKER WROBEL}

Let $E_{1}, E_{2}, E_{3}, E_{4}$ be four locally convex Hausdorff spaces (1.c.s.); denote by $\mathscr{L}_{b}\left(E_{i}, E_{k}\right)$ the set of all continuous linear operators from $E_{i}$ into $E_{k}$ with the topology of uniform convergence on bounded subsets of $E_{i}$. Given two linear operators $f \in \mathscr{L}\left(E_{1}, E_{2}\right)$ and $g \in \mathscr{L}\left(E_{3}, E_{4}\right)$, consider the generalized adjoint operator $\operatorname{Hom}(f, g): \mathscr{L}_{b}\left(E_{2}, E_{3} \rightarrow \mathscr{L}_{b}\left(E_{1}, E_{4}\right)\right.$ defined by $u \rightarrow \operatorname{Hom}(f, g) u=g \circ u \circ f$. This paper deals with transformation properties of $\operatorname{Hom}(f, g)$ and their interactions with those of $f$ and $g$. This purpose may be illustrated by a result due to $K$. Vala which generalizes Schauder's wellknown theorem concerning precompact operators and their adjoints on normed spaces: Let all spaces under consideration be normed, let $f$ and $g$ both be nonzero. Then Hom $(f, g)$ is a precompact operator if and only if $f$ and $g$ are precompact operators. In the present paper bounded and precompact operators on 1.c.s. are investigated.

1. Introduction. Unless otherwise stated notation used throughout this paper will be that of Schaefer [6]. $E_{i}(i \in N)$ will always denote a l.c.s. over the field of complex numbers $C, \mathscr{P}_{i}$ denotes the set of all continuous seminorms, and $\mathscr{B}\left(E_{i}\right)$ a fundamental system of bounded subsets of $E_{i}$. By $U_{p_{i}}$ denote the closed, convex, circled neighborhood of zero $\left\{x \in E_{i}: P_{i}(x) \leqq 1\right\}$ in $E_{i}$. If $B_{i}$ runs through $\mathscr{B}\left(E_{i}\right), p_{k}$ through $\mathscr{P}_{k}$, the family

$$
W\left(B_{i}, U_{p_{k}}\right)=\left\{u \in \mathscr{L}\left(E_{i}, E_{k}\right): u\left(B_{i}\right) \subset U_{p_{k}}\right\}
$$

is a neighborhood base of zero in $\mathscr{L}_{b}\left(E_{i}, E_{k}\right)$.

Definition 1.1. A linear operator $u: E_{i} \rightarrow E_{k}$ is said to be precompact (compact or bounded) if there exists a neighborhood of zero $U_{p_{i}}$ in $E_{i}$ such that $u\left(U_{p_{i}}\right)$ is a precompact (relatively compact or bounded) subset of $E_{k}$. A linear operator $u: E_{i} \rightarrow E_{k}$ is said to be semi-precompact if $u$ maps bounded subsets of $E_{i}$ into precompact subsets of $E_{k}$.

Of course bounded linear operators are continuous, whereas semi-precompact operators need not. Let $u \in \mathscr{L}\left(E_{1}, E_{2}\right), w \in \mathscr{L}\left(E_{3}, E_{4}\right)$, and let $v \in \mathscr{L}\left(E_{2}, E_{3}\right)$ be a semi-precompact (precompact, compact, or bounded) operator. Then $v \circ u \in \mathscr{L}\left(E_{1}, E_{3}\right)$ and $w \circ v \mathscr{L}\left(E_{2}, E_{4}\right)$ are semi-precompact (precompact, compact, or bounded) operators. 
A subset $\mathscr{H} \subset \mathscr{L}\left(E_{i}, E_{k}\right)$ is said to be collectively precompact if there exists a neighborhood of zero $U_{p_{i}}$ in $E_{i}$ such that $\mathscr{H}\left(U_{p_{i}}\right)=$ $\left\{u(x): u \in \mathscr{H}, x \in U_{p_{i}}\right\}$ is a precompact subset of $E_{k}$. Let $f \in \mathscr{L}\left(E_{1}, E_{2}\right)$ and $g \in \mathscr{L}\left(E_{3}, E_{4}\right)$ both be nonzero. Then the linear mapping $\operatorname{Hom}(f, g): \mathscr{L}_{b}\left(E_{2}, E_{3}\right) \rightarrow \mathscr{L}_{b}\left(E_{1}, E_{4}\right)$ given by $u \rightarrow \operatorname{Hom}(f, g) u=g \circ u \circ f$ is continuous, as an easy calculation shows. By setting $E_{3}=E_{4}=C$ and $g=\mathrm{id}_{C}$ (identity map on $C$ ) Hom $(f, g)$ becomes the adjoint operator $f^{\prime}$ of $f$. That is why one may call $\operatorname{Hom}(f, g)$ a generalized adjoint operator. In generalizing Schauder's well-known theorem Vala [7] has obtained the following result.

THEOREM 1.1. Let $E_{1}, E_{2}, E_{3}, E_{4}$ denote four normed linear spaces, let $f \in \mathscr{L}\left(E_{1}, E_{2}\right)$ and $g \in \mathscr{L}\left(E_{3}, E_{4}\right)$ both be nonzero. Then the mapping

$$
\operatorname{Hom}(f, g): \mathscr{L}_{b}\left(E_{2}, E_{3}\right) \longrightarrow \mathscr{L}_{b}\left(E_{1}, E_{4}\right)
$$

given by $u \rightarrow \operatorname{Hom}(f, g) u=g \circ u \circ f$ is precompact if and only if both $f$ and $g$ are precompact.

We shall be interested in similar results in case of l.c.s.. For that purpose the notion of an infrabarrelled 1.c.s. is needed. The definition given below is not entirely standard but is easily proved equivalent to the standard one (see Horváth [4, Definition 2, p. 217]). Just this definition gives more insight in why infrabarrelled spaces are involved.

DeFinition 1.1. A l.c.s. $E_{1}$ is said to be infrabarrelled if each bounded subset of $\mathscr{L}_{b}\left(E_{1}, E_{2}\right)$ is equicontinuous for all l.c.s. $E_{2}$.

As in normed linear spaces semi-precompact operators are precompact, the following result due to Apiola [1] and Geue [3] is a generalization of Vala's theorem.

THEOREM 1.2. Let $E_{1}, E_{2}, E_{3}, E_{4}$ denote four l.c.s. and assume in addition $E_{2}$ is infrabarrelled. Let $f \in \mathscr{L}\left(E_{1}, E_{2}\right)$ and $g \in \mathscr{L}\left(E_{3}, E_{4}\right)$ both be nonzero. Then

$$
\operatorname{Hom}(f, g): \mathscr{L}_{b}\left(E_{2}, E_{3}\right) \longrightarrow \mathscr{L}_{b}\left(E_{1}, E_{4}\right)
$$

given by $u \rightarrow \operatorname{Hom}(f, g) u=g \circ u \circ f$ is a semi-precompact continuous linear operator if and only if both $f$ and $g$ are semi-precompact.

REMARK. If one drops the assumption of $E_{2}$ being infra- 
barrelled, the implication 'Hom $(f, g)$ semi-precompact $\curvearrowright$ both $f$ and $g$ semi-precompact' remains true, whereas the converse implication in general becomes false (see Apiola [1, Theorem 3.3.]).

In this paper we shall be interested in what happens if we consider precompact or bounded linear operators instead of semiprecompact continuous linear operators. Considering the precompact situation the following result due to Floret $[2, \S 13]$ is rather instructive.

THEOREM 1.3. There exists a reflexive Fréchet space $E_{1}, a$ Banach space $E_{2}$, and a semi-precompact operator $f \in \mathscr{L}\left(E_{1}, E_{2}\right)$ such that the adjoint operator $f^{\prime}: E_{2 b}^{\prime} \rightarrow E_{1 b}^{\prime}$ of $f$ is precompact without $f$ being precompact itself.

REMARK. The theorem demonstrates that if $\operatorname{Hom}(f, g)$ is precompact, $f$ in general is not. But as $E_{1}$ is a reflexive l.c.s. this result also shows that $\operatorname{Hom}(f, g)$ in general will not be precompact even if both $f$ and $g$ are.

2. Transformation properties of bounded operators. In dealing with bounded operators we have

THEOREM 2.1. Let $E_{1}, E_{2}, E_{3}, E_{4}$ denote four l.c.s., and let $f \in \mathscr{L}\left(E_{1}, E_{2}\right), g \in \mathscr{L}\left(E_{3}, E_{4}\right)$. Then

(i) If $f$ and $g$ both are bounded linear operators, then Hom $(f, g)$ is bounded.

(ii) Let $f$ and $g$ both be nonzero and assume in addition $E_{1}$ is infrabarrelled. Then $\operatorname{Hom}(f, g)$ is bounded if and only if both $f$ and $g$ are bounded operators. If $\operatorname{Hom}(f, g)$ is precompact, then $g$ is a precompact operator.

The following lemma gives more insight into the proof of the theorem.

Lemma 2.1. Let $E_{1}$ and $E_{2}$ denote two l.c.s., let $x_{0} \in B_{1} \in \mathscr{B}\left(E_{1}\right)$ and $p_{1} \in \mathscr{P}_{1}$ such that $p_{1}\left(B_{1}\right)=\sup _{x \in B_{1}} p_{1}(x)=p_{1}\left(x_{0}\right)=1$. Then we have

$$
\left\{u\left(x_{0}\right): u \in W\left(B_{1}, U_{p_{2}}\right) \text { and } \operatorname{dim} u\left(E_{1}\right)=1\right\}=U_{p_{2}}
$$

for all $p_{2} \in \mathscr{P}_{2}$.

Proof. The inclusion $\subset$ is evident. For the converse inclusion let $y_{0} \in U_{p_{2}}$ be given. By the theorem of Hahn-Banach there exists 
a $\varphi \in E_{1}^{\prime}$ such that $\varphi\left(x_{0}\right)=1$ and $|\varphi(x)| \leqq p_{1}(x)$ for all $x \in E_{1}$. Now the mapping $x \rightarrow u(x)=\varphi(x) y_{0}$ is in $\mathscr{L}\left(E_{1}, E_{2}\right)$. Furthermore $u\left(x_{0}\right)=$ $y_{0}$ and $p_{2}\left(u\left(B_{1}\right)\right)=\left|\varphi\left(B_{1}\right)\right| p_{2}\left(y_{0}\right) \leqq 1$, therefore $u \in W\left(B_{1}, U_{p_{2}}\right)$. This completes the proof.

Proof of Theorem 2.1. For the demonstration of (i) let $p_{1} \in \mathscr{P}_{1}$ and $p_{3} \in \mathscr{P}_{3}$ denote two semi-norms such that $f\left(U_{p_{1}}\right)$ and $g\left(U_{p_{3}}\right)$ are bounded sets in $E_{2}$ and $E_{4}$. Then we get the following factorization:

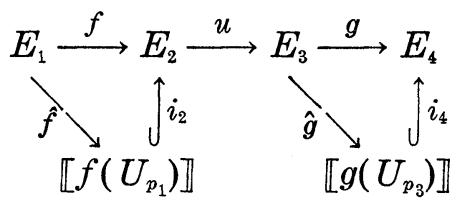

where for a convex, circled, bounded subset $A \subset E_{i}$, $A A \rrbracket$ denotes the vector spaces spanned by $A$ provided with the norm defined by the Minkowski functional of $A$. The mapping $\operatorname{Hom}\left(i_{2}, \hat{g}\right): \mathscr{L}_{b}\left(E_{2}, E_{3}\right) \rightarrow$ $\mathscr{L}_{b}\left(\llbracket f\left(U_{p_{1}}\right) \rrbracket, \llbracket g\left(U_{p_{3}}\right) \rrbracket\right)$ is bounded, because it is a continuous linear mapping into a normed space. Hence the composed mapping $\operatorname{Hom}(f, g)=\operatorname{Hom}\left(\hat{f}, i_{4}\right) \circ \operatorname{Hom}\left(i_{2}, \hat{g}\right)$ is bounded. For the demonstration of (ii) let $W\left(B_{2}, U_{p_{3}}\right)$ be a neighborhood of zero in $\mathscr{L}_{b}\left(E_{2}, E_{3}\right)$ such that $\operatorname{Hom}(f, g) W\left(B_{2}, U_{p_{3}}\right)$ is a bounded (precompact) subset of $\mathscr{L}_{b}\left(E_{1}, E_{4}\right)$. As $E_{1}$ is infrabarrelled, this set is equicontinuous. Now we find a semi-norm $p_{2} \in \mathscr{P}_{2}$ and a $x_{0} \in E_{1}$ such that $p_{2}\left(f\left(x_{0}\right)\right)=1$ and $p_{2}\left(B_{2}\right) \leqq 1$. By taking $B_{2} \cup\left\{f\left(x_{0}\right)\right\}$ instead of $B_{2}$, we may assume $f\left(x_{0}\right) \in B_{2}$ Then by Lemma 2.1. we have $U_{p_{3}}=\left\{u\left(f\left(x_{0}\right)\right): u \in W\left(B_{2}, U_{p_{3}}\right)\right.$ and $\left.\operatorname{dim} u\left(E_{2}\right)=1\right\}$. Hence $g\left(U_{p_{3}}\right)=\left\{g \circ u \circ f\left(x_{0}\right): u \in W\left(B_{2}, U_{p_{3}}\right)\right.$ and $\left.\operatorname{dim} u\left(E_{2}\right)=1\right\} \subset \operatorname{Hom}(f, g) W\left(B_{2}, U_{p_{3}}\right)\left(x_{0}\right)$ is a bounded (precompact) subset of $E_{4}$. Thus $g$ is a bounded (precompact) linear operator. To show that $f$ is also bounded, let $z_{0} \in E_{3}$ such that $g\left(z_{0}\right) \neq 0$. Now obviously $\mathscr{L}_{b}\left(E_{2}, C z_{0}\right)$ and $\mathscr{L}_{b}\left(E_{1}, C g\left(z_{0}\right)\right)$ are complemented subspaces of $\mathscr{L}_{b}\left(E_{2}, E_{3}\right)$ and $\mathscr{L}_{b}\left(E_{1}, E_{4}\right)$. Furthermore $\varphi \rightarrow \varphi \otimes z_{0}$ and $\psi \rightarrow \psi \otimes g\left(z_{0}\right)$ are canonical isomorphisms from $\mathscr{L}_{b}\left(E_{2}, C\right)$ and $\mathscr{L}_{b}\left(E_{1}, C\right)$ onto $L_{b}\left(E_{2}, C z_{0}\right)$ and $\mathscr{L}_{b}\left(E_{1}, C g\left(z_{0}\right)\right)$. Thus we are in the situation of the following diagram:

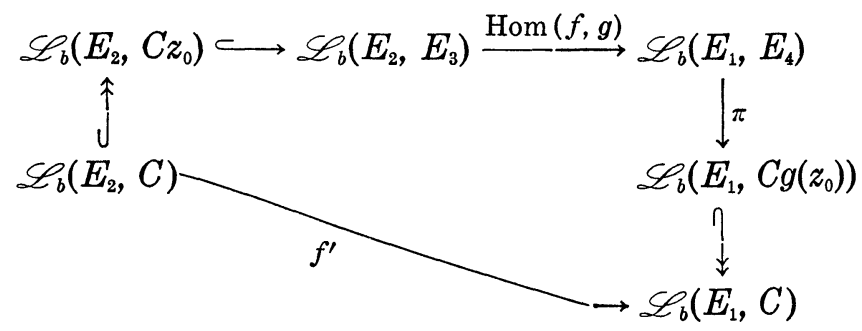

The composed mapping 


$$
\varphi \longrightarrow \varphi \otimes z_{0} \longrightarrow g \circ\left(\varphi \otimes z_{0}\right) \circ f \longrightarrow \varphi \circ f \otimes g\left(z_{0}\right) \longrightarrow \varphi \circ f
$$

from $\mathscr{L}_{b}\left(E_{2}, C\right)$ into $\mathscr{L}_{b}\left(E_{1}, C\right)$ is the adjoint operator $f^{\prime}$ of $f$. As Hom $(f, g)$ is a bounded operator, so is $f^{\prime}$. Hence there is a bounded subset $B_{2}$ of $E_{2}$ such that $f^{\prime}\left(B_{2}^{0}\right)$ is bounded in $E_{1 b}^{\prime}=\mathscr{L}_{b}\left(E_{1}, C\right)$. Because of $\left(f^{\prime}\left(B_{2}^{0}\right)\right)^{0}=\left(f^{\prime \prime}\right)^{-1}\left(B_{2}^{00}\right)$ we get $f^{\prime \prime}\left(\left(f^{\prime}\left(B_{2}^{0}\right)^{0}\right) \subset B_{2}^{00}\right.$. As $E_{1}$ is infrabarrelled $E_{1 b}^{\prime \prime}$ induces the given topology on $E_{1}$. Thus $f=\left.f^{\prime \prime}\right|_{E_{1}}$ is a bounded operator. This completes the proof.

Especially, the adjoint operator $f^{\prime}: E_{2 b}^{\prime} \rightarrow E_{1 b}^{\prime}$ of a bounded operator $f \in \mathscr{L}\left(E_{1}, E_{2}\right)$ is bounded, and if $E_{1}$ is infrabarrelled also the converse holds. Without $E_{1}$ being infrabarrelled, the last statement in general no longer remains true. To give an example consider the mapping $i d_{E}: E_{\sigma} \rightarrow E_{\sigma}$ where $E$ denotes an infinite dimensional normed linear space and $\sigma$ denotes the $\sigma\left(E, E^{\prime}\right)$-topology on $E$. Then $\left(i d_{E}\right)^{\prime}=i d_{E^{\prime}}: E_{b}^{\prime} \rightarrow E_{b}^{\prime}$ is a bounded operator, whereas $i d_{E}: E_{\sigma} \rightarrow E_{\sigma}$ is not.

3. Transformation properties of precompact operators. As we have learned from Theorem 1.3 there exists no precompact version of Theorem 2.1 without further assumption put on the l.c.s. or the operators involved. In general only the following holds

THEOREM 3.1. Let $E_{1}, E_{2}, E_{3}, E_{4}$ denote four 1.c.s., and let $f \in \mathscr{L}\left(E_{1}, E_{2}\right), g \in \mathscr{L}\left(E_{3}, E_{4}\right)$ both be bounded operators. Then

(i) $\operatorname{Hom}(f, g)$ is a bounded operator. If in addition $E_{2}$ is infrabarrelled, $f$ and $g$ both are precompact (semi-precompact would be sufficient), then $\operatorname{Hom}(f, g)$ is bounded and semi-precompact.

(ii) If $g$ is a precompact operator, then there exists a neighborhood of zero $W\left(B_{2}, U_{p_{3}}\right)$ in $\mathscr{L}_{b}\left(E_{2}, E_{3}\right)$ such that $\operatorname{Hom}(f, g) W\left(B_{2}, U_{p_{3}}\right)$ is a collectively precompact subset of $\mathscr{L}\left(E_{1}, E_{4}\right)$.

Proof. Only (ii) is to be shown. For this purpose let $B_{2} \in \mathscr{B}\left(E_{2}\right)$ and $U_{p_{1}}, U_{p_{3}}$ be given such that $f\left(U_{p_{1}}\right) \subset B_{2}$, and $g\left(U_{p_{3}}\right)$ is precompact. Then the following inclusions hold

$\operatorname{Hom}(f, g) W\left(B_{2}, U_{p_{3}}\right)\left(U_{p_{1}}\right) \subset\left\{g \circ u(y): y \in B_{2}, u \in W\left(B_{2}, U_{p_{3}}\right)\right\} \subset g\left(U_{p_{3}}\right)$.

Since $g\left(U_{p_{3}}\right)$ is precompact by assumption, we are done.

Now we shall give conditions making sure that $\operatorname{Hom}(f, g)$ becomes a precompact operator. The following theorem is a generalization of a result due to Ringrose [5].

THEOREM 3.2. Let $E_{1}, E_{2}, E_{3}, E_{4}, E_{5}$ denote five l.c.s., and let $f_{1} \in \mathscr{L}\left(E_{1}, E_{2}\right)$ and $g \in \mathscr{L}\left(E_{4}, E_{5}\right)$ both be precompact, let $f_{2} \in \mathscr{L}\left(E_{2}, E_{3}\right)$ 
be bounded. Then the mapping

$$
\operatorname{Hom}\left(f_{2} \circ f_{1}, g\right): \mathscr{L}_{b}\left(E_{3}, E_{4}\right) \longrightarrow \mathscr{L}_{b}\left(E_{1}, E_{5}\right)
$$

defined by $u \rightarrow \operatorname{Hom}\left(f_{2} \circ f_{1}, g\right) u=g \circ u \circ f_{2} \circ f_{1}$ is precompact.

Proof. By $E_{p_{i}}$ we denote the normed space $\left(E_{i} / p_{i}^{-1}(o), p_{i}\right)$. Let $U_{p_{1}}, U_{p_{2}}$, and $U_{p_{4}}$ denote three neighborhoods of zero such that $f_{1}\left(U_{p_{1}}\right)$ and $g\left(U_{p_{4}}\right)$ both are precompact, and $f_{2}\left(U_{p_{2}}\right)$ is bounded. Then we get the following factorization

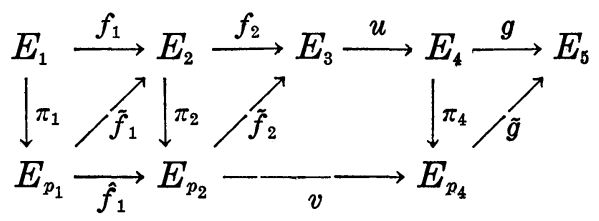

Now the following mappings are continuous:

$$
\begin{aligned}
& \operatorname{Hom}\left(\hat{f}_{1}, \widetilde{g}\right): \mathscr{L}_{b}\left(E_{p_{2}}, E_{p_{4}}\right) \longrightarrow \mathscr{L}_{b}\left(E_{p_{1}}, E_{5}\right) \\
& \operatorname{Hom}\left(\widetilde{f}_{2}, \pi_{4}\right): \mathscr{L}_{b}\left(E_{3}, E_{4}\right) \longrightarrow \mathscr{L}_{b}\left(E_{p_{2}}, E_{p_{4}}\right)
\end{aligned}
$$

$w \rightarrow \gamma(w)=w \circ \pi_{1}$ from $\mathscr{L}_{b}\left(E_{p_{1}}, E_{5}\right)$ into $\mathscr{L}_{b}\left(E_{1}, E_{5}\right)$. But by Theorem 1.2 the first mapping is semi-precompact, hence precompact, as $\mathscr{L}_{b}\left(E_{p_{2}}, E_{p_{4}}\right)$ is a normed space. Hence the composed mapping $\operatorname{Hom}\left(f_{2} \circ f_{1}, g\right)=\gamma \circ \operatorname{Hom}\left(\hat{f}_{1}, \widetilde{g}\right) \circ \operatorname{Hom}\left(\widetilde{f}_{2}, \pi_{4}\right)$ is a precompact operator. This completes the proof.

Now we shall give some applications of this theorem.

Corollary 1. Let $E_{1}, E_{2}, E_{3}$ denote three l.c.s., let $f_{1} \in \mathscr{L}\left(E_{1}, E_{2}\right)$ be a precompact operator, and let $f_{2} \in \mathscr{L}\left(E_{2}, E_{3}\right)$ be a bounded operator. Then the adjoint operator

$$
\left(f_{2} \circ f_{1}\right)^{\prime}=f_{1}^{\prime} \circ f_{2}^{\prime}: E_{3 b}^{\prime} \longrightarrow E_{1 b}^{\prime}
$$

is precompact.

Especially. Let $f$ be a precompact endomorphism of $E_{1}$. Then $\left(f^{\prime}\right)^{2}: E_{1 b}^{\prime} \rightarrow E_{1 b}^{\prime}$ is precompact.

A proof of this corollary is immediately obtained from Theorem 3.2 by setting $E_{4}=E_{5}=C$ and $g=\mathrm{id}_{c}$. The corollary is originally due to Ringrose [5]. The assumptions put on $f_{1}$ may be weakened: Let $E_{2}$ be infrabarrelled and let $f_{1}$ be semi-precompact instead of being precompact. Then by Theorem $1.2 f_{1}^{\prime}: E_{2 b}^{\prime} \rightarrow E_{1 b}^{\prime}$ is semiprecompact, and $f_{2}^{\prime}: E_{3 b}^{\prime} \rightarrow E_{2 b}^{\prime}$ is bounded by Theorem 2.1. Hence the composed operator $f_{1}^{\prime} \circ f_{2}^{\prime}$ is precompact. Indeed, by using the 
same arguments as Ringrose in [5], one can show, that $f_{1}^{\prime} \circ f_{2}^{\prime}$ is even compact.

Corollary 2. Let $E_{1}, E_{2}, E_{3}, E_{4}$ denote four l.c.s., let $f \in$ $\mathscr{L}\left(E_{1}, E_{2}\right)$ and $g \in \mathscr{L}\left(E_{3}, E_{4}\right)$.

(i) Let $E_{1}$ be a Schwartz space (for a definition and further properties of these spaces see Horváth [4]), let $f$ be bounded, and let $g$ be precompact. The $\operatorname{Hom}(f, g)$ is a precompact operator.

(ii) Let $E_{1}$ denote an infrabarrelled Schwartz space, let $f$ and $g$ both be nonzero. Then Hom $(f, g)$ is precompact if and only if $f$ and $g$ both are precompact.

(iii) Let $E_{2}$ be a Fréchet space, let $f$ and $g$ both be precompact. Then $\operatorname{Hom}(f, g)$ is a precompact operator.

Proof. Let $f \in \mathscr{L}\left(E_{1}, E_{2}\right)$ be a bounded operator. Then there exists a suitable neighborhood of zero $U_{p_{1}}$ in $E_{1}$ such that we have the following factorization

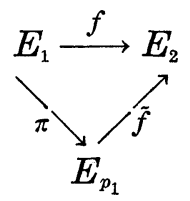

By Horváth [4, Proposition 3, p. 275] we may assume that $\pi$ is precompact if $E_{1}$ is a Schwartz space. Thus we are in the situation of the following diagram

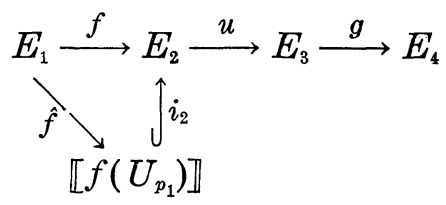

where $\hat{f}$ is a precompact operator. Hence $\operatorname{Hom}(f, g)=\operatorname{Hom}\left(i_{2} \circ \hat{f}, g\right)$ is precompact by Theorem 3.2. Now assume Hom $(f, g)$ is precompact. Then by Theorem $2.1 f$ is bounded and $g$ is precompact. As $E_{1}$ is a Schwartz space $f$ is precompact by the first diagram.

To end this proof a result concerning compact subsets of a Fréchet space is needed, which can easily be deduced from Schaefer [5, Corollary 1, p. 151]:

If $B$ is a convex, circled, compact subset of a Fréchet space $E$, then there exists another convex, circled, compact subset $A \subset E$ containing $B$ such that the embedding $\llbracket B \rrbracket \subset \llbracket A \rrbracket$ is a compact mapping. 
Hence in (iii) we are in the situation of the following diagram

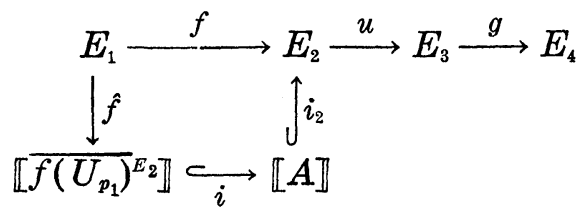

Where $\llbracket \overline{f\left(U_{p_{1}}\right)^{E}} \rrbracket \underset{i}{\longrightarrow} \llbracket A \rrbracket$ is compact ( $A$ a convex, circled, compact subset of $\left.E_{2}\right)$. Then by Theorem 3.2. $\operatorname{Hom}(f, g)=\operatorname{Hom}\left(i_{2} \circ(i \circ \hat{f}), g\right)$ is precompact. This completes the proof.

I want to express my gratitude to the referee for his valuable and detailed suggestions concerning the first version of this paper.

\section{REFERENCES}

1. H. Apiola, On the tensorproduct and product $\operatorname{Hom}(f, g)$ of compact operators in locally convex topological vector spaces, Ann. Acad. Sci. Fenn. Ser., AI No. 544 (1973), $33 \mathrm{pp}$.

2. K. Floret, Lokalkonvexe Sequenzen mit kompakten Abbildungen, J. reine angew. Math., 247 (1971) 155-195.

3. A. S. Geue, Precompact and collectively semi-precompact sets of semi-precompact continuous linear operators, Pacific J. Math., 52 (1974) 377-401.

4. J. Horváth, Topological Vector Spaces and Distributions, Volume I, AddisonWesley, 1966.

5. J. R. Ringrose, Complete continuity conditions on linear operators, Proc. London Math. Soc., (3) 8 (1958), 343-356.

6. H. H. Schaefer, Topological Vector Spaces, Springer-Verlag, New York 1971.

7. K. Vala, On compact sets of compact operators, Ann. Acad. Sci. Fenn. Ser. AI No. 351 (1964), 9 pp.

Received July 22, 1975 and in revised form November 13, 1975.

Mathematisches Seminar der UNiversität

D-23 Kiel 1

OLSHAUSENSTR. $40-60$

Fed. Rep. Germany 


\section{PACIFIC JOURNAL OF MATHEMATICS}

\section{EDITORS}

RICHARD ARENS (Managing Editor)

University of California

Los Angeles, California 90024

\author{
R. A. Beaumont \\ University of Washington \\ Seattle, Washington 98105
}

\section{J. DugundjI}

Department of Mathematics University of Southern California Los Angeles, California 90007

D. Gilbarg and J. Milgram

Stanford University

Stanford, California 94305

\section{ASSOCIATE EDITORS}
E. F. BECKENBACH
B. H. NeumanN
F. WOLF
K. YoshidA

\section{SUPPORTING INSTITUTIONS}

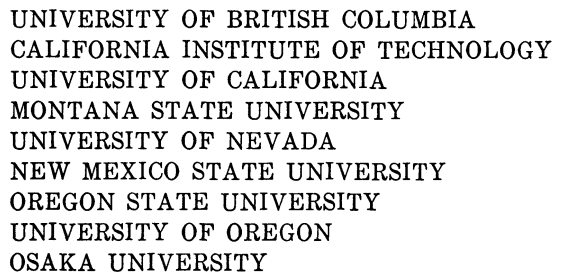

UNIVERSITY OF BRITISH COLUMBIA CALIFORNIA INSTITUTE OF TECHNOLOGY UNIVERSITY OF CALIFORNIA MONTANA STATE UNIVERSITY UNIVERSITY OF NEVADA NEW MEXICO STATE UNIVERSITY OSAKA UNIVERSITY OREGON STATE UNIVERSITY UNIVERSITY OF OREGON

\author{
UNIVERSITY OF SOUTHERN CALIFORNIA \\ STANFORD UNIVERSITY \\ UNIVERSITY OF TOKYO \\ UNIVERSITY OF UTAH \\ WASHINGTON STATE UNIVERSITY \\ UNIVERSITY OF WASHINGTON \\ AMERICAN MATHEMATICAL SOCIETY
}

The Supporting Institutions listed above contribute to the cost of publication of this Journal, but they are not owners or publishers and have no responsibility for its content or policies.

Mathematical papers intended for publication in the Pacific Journal of Mathematics should be in typed form or offset-reproduced, (not dittoed), double spaced with large margins. Please do not use built up fractions in the text of your manuscript. You may however, use them in the displayed equations. Underline Greek letters in red, German in green, and script in blue. The first paragraph or two must be capable of being used separately as a synopsis of the entire paper. Items of the bibliography should not be cited there unless absolutely necessary, in which case they must be identified by author and Journal, rather than by item number. Manuscripts, in triplicate, may be sent to any one of the editors. Please classify according to the scheme of Math. Reviews, Index to Vol. 39. All other communications should be addressed to the managing editor, or Elaine Barth, University of California, Los Angeles, California, 90024.

The Pacific Journal of Mathematics expects the author's institution to pay page charges, and reserves the right to delay publication for nonpayment of charges in case of financial emergency.

100 reprints are provided free for each article, only if page charges have been substantially paid. Additional copies may be obtained at cost in multiples of 50 .

The Pacific Journal of Mathematics is issued monthly as of January 1966. Regular subscription rate: $\$ 72.00$ a year $(6$ Vols., 12 issues). Special rate: $\$ 36.00$ a year to individual members of supporting institutions.

Subscriptions, orders for back numbers, and changes of address should be sent to Pacific Journal of Mathematics, 103 Highland Boulevard, Berkeley, California, 94708.

PUBLISHED BY PACIFIC JOURNAL OF MATHEMATICS, A NON-PROFIT CORPORATION

Printed at Kokusai Bunken Insatsusha (International Academic Printing Co., Ltd.), 8-8, 3-chome, Takadanobaba, Shinjuku-ku, Tokyo 160, Japan. 


\section{Pacific Journal of Mathematics}

\section{Vol. 61, No. 2 December, 1975}

Graham Donald Allen, Francis Joseph Narcowich and James Patrick Williams, An operator version of a theorem of Kolmogorov .......................

Joel Hilary Anderson and Ciprian Foias, Properties which normal operators share with normal derivations and related operators . . . . . . . . . . . . . . . . . . . . .

Constantin Gelu Apostol and Norberto Salinas, Nilpotent approximations and

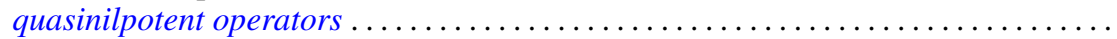

James M. Briggs, Jr., Finitely generated ideals in regular $F$-algebras . . . . . . . . . . .

Frank Benjamin Cannonito and Ronald Wallace Gatterdam, The word problem and power problem in 1-relator groups are primitive recursive ..................

Clifton Earle Corzatt, Permutation polynomials over the rational numbers ...........

L. S. Dube, An inversion of the $S_{2}$ transform for generalized functions . . . . . . . . . . William Richard Emerson, Averaging strongly subadditive set functions in unimodular

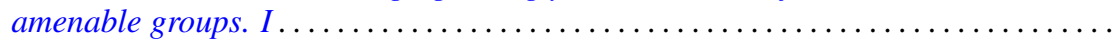

Barry J. Gardner, Semi-simple radical classes of algebras and attainability of

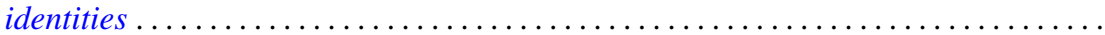

Irving Leonard Glicksberg, Removable discontinuities of A-holomorphic functions ....

Fred Halpern, Transfer theorems for topological structures . . . . . . . . . . . . . . .

H. B. Hamilton, T. E. Nordahl and Takayuki Tamura, Commutative cancellative

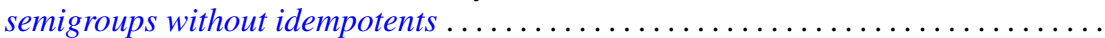

Melvin Hochster, An obstruction to lifting cyclic modules .....................

Alistair H. Lachlan, Theories with a finite number of models in an uncountable power

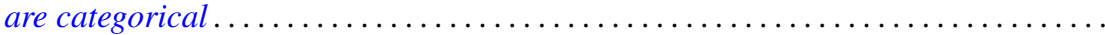

Kjeld Laursen, Continuity of linear maps from $C^{*}$-algebras . . . . . . . . . . . . .

Tsai Sheng Liu, Oscillation of even order differential equations with deviating arguments ....

Jorge Martinez, Doubling chains, singular elements and hyper- $Z$

Mehdi Radjabalipour and Heydar Radjavi, On the geometry of num Thomas I. Seidman, The solution of singular equations, I. Linear equations in Hilbert

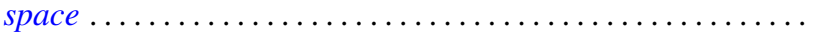

R. James Tomkins, Properties of martingale-like sequences ......

Alfons Van Daele, A Radon Nikodým theorem for weights on von Neumann

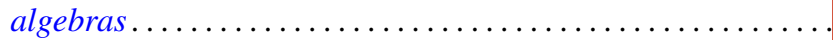

Kenneth S. Williams, On Euler's criterion for quintic nonresidues

Scott Andrew Wolpert, Noncompleteness of the Weil-Petersson metric for Teichmüller

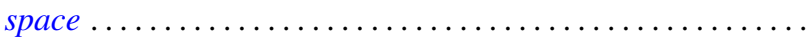

Volker Wrobel, Some generalizations of Schauder's theorem in locally convex

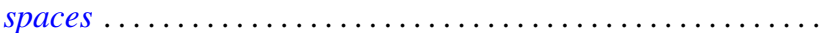

Kelly Denis McKennon, Corrections to: "Multipliers of type $(p, p)$ "; "Multipliers of type $(p, p)$ and multipliers of the group $L_{p}$-algebras"; "Multipliers and the

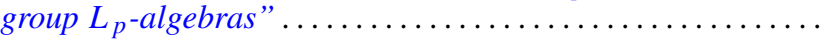

Andrew M. W. Glass, W. Charles (Wilbur) Holland Jr. and Stephen H. McCleary, Correction to: " $a *$-closures to completely distributive lattice-ordered

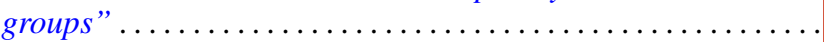

Zvi Arad and George Isaac Glauberman, Correction to: "A characteristic subgroup of

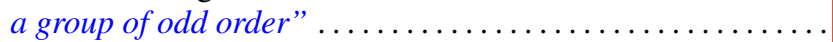

Roger W. Barnard and John Lawson Lewis, Correction to: "Subordination theorems

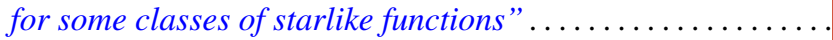

